\title{
MỘT SỐ ĐÁNH GIÁ THỐNG KÊ VỀ TÍNH CHẤT CỦA BÃO BIỂN ĐÔNG VÀ VƯNG BỜ BIỂN VIẸTT NAM GIAI ĐOẠN 1951-2013
}

\author{
Dư Văn Toán ${ }^{1 *}$, Nguyễn Quốc Trinh ${ }^{2}$, Phạm Văn Tiến ${ }^{3}$, \\ Lưu Thị Toán ${ }^{4}$, Lưu Thành Trung ${ }^{5}$, Nguyễn Ngọc Tiến ${ }^{6}$ \\ ${ }^{1}$ Viện Nghiên cứu quản lý biển và hải đảo \\ ${ }^{2}$ Trung tâm khí tượng thủy văn Quốc gia \\ ${ }^{3}$ Viện Khoa học Khí tượng Thủy văn và Môi trường \\ ${ }^{4}$ Đại Học Quốc Gia Hà Nội \\ ${ }^{5}$ Vụ Khoa học và Công nghệ-Bộ Tài nguyên và Môi trường \\ ${ }^{6}$ Viện Địa chất và Địa vật lý biển-Viện Hàn lâm Khoa học và Công nghệ Việt Nam \\ "Email: duvantoan@gmail.com
}

Ngày nhận bài: 10-1-2014

TÓM TÄT: Bài báo trình bày về phuoong pháp đánh giá phân tích thống kê bão biển Việt Nam giai đoạn 1951-2013 và các kết quả thu được. Các kết quả cho thấy là tổng số bão Biển Đông là 695 conn với trung bình năm là hơn 11 cơn và tại bò̀ biển Việt Nam là 327 cơn với trung bình là 5,2 conn/năm. Tháng hoạt động chính của mùa bão là 7,8 và 9 , số luợng điểm đổ bộ vào Việt Nam chia theo 7 vùng và có phân bố giảm dần tù̀ vùng I phía Bắc đến vùng VII phía Nam, gió có tốc độ cực đại trong các con bão là khoảng $53 \mathrm{~m} / \mathrm{s}$, đạt lớn nhất năm 2006 với $58 \mathrm{~m} / \mathrm{s}$, lương mua cưc đại trong bão khoảng trên $400 \mathrm{~mm}$. Bài báo cũng đura ra một số nhận định về quy luật biến thiên của bão biển Việt Nam trong tuơng lai nhằm phục vu cho công tác đảm bảo thông tin thờ tiết và phòng chống thiên tai.

Tù khóa: Bão biển Việt Nam, bò biển, điểm đổ bộ, gió cưc đại, mura cực đại, tần suất bão.

\section{MỞ ĐẦU}

Bão trên thế giới có nhiều cách gọi khác nhau: ở vùng châu Á Thái Bình Dương bão được gọi là "Typhoon"; ở vùng Ấn Độ Dương người ta gọi bão là "Cyclone"; ở vùng Đại Tây Dương người ta gọi bão là "Uragan" hay "Hurricane"; ở châu Úc người ta gọi bão là "Villy-Villy". Tất cả những tên gọi đó được quy tụ lại dưới một tên cơ bản chung là "Tropical Cyclone" - bão hay xoáy thuận nhiệt đới (XTNĐ).

Với vùng biển Việt Nam, có các nghiên cứu về bão và biến động bão biển giai đoạn 19802000 của các nhà khoa học Liên Xô và quốc tế [10-20] đã chỉ ra sự biến động khác thường về tần suất và cường độ bão, xu thế bão và ảnh hưởng tới dòng chảy-hoàn lưu, sóng biển vịnh Bắc Bộ, vịnh Thái Lan và toàn biển Đông. Các nhà khoa học Việt Nam cũng đã có hàng loạt nghiên cứu về khí hậu và bão biển [1-9] với các kêt quả tương đối khác nhau. Đặc biệt nghiên cứu chi tiết mới nhất cho thấy có sự biến động đáng kể của trường nhiệt độ nước mặt biển và hoạt động của bão nhiệt đới trên khu vực Biển Đông trong những thập kỷ gần đây [3]; số lượng trung bình năm của bão và siêu bão dao động theo các chu kỳ dài từ hai năm đến nhiều chục năm [4]. Trong năm thập kỷ gần đây, số lượng bão ảnh hưởng trực tiếp đến ven bờ vịnh Bắc Bộ giảm, trong khi ở Nam Trung Bộ và Nam Bộ lại gia tăng. Nguyễn Văn Tuyên (2007) [8] đã nghiên cứu sự phân bố của bão, theo đó bão được phân loại theo vùng ảnh hưởng và theo cường độ rồi phân tích xu hướng hoạt động. Kết quả phân tích cho thấy, trong thời kỳ 1951-2006, hoạt động của bão trên khu vực Tây Bắc Thái Bình Dương (TBTBD) có xu hướng giảm về số lượng, trong đó số cơn bão 
yếu và trung bình có xu hướng giảm, còn số cơn bão mạnh lại có xu hướng tăng lên. Trên khu vực Biển Đông, những cơn bão vào Biển Đông nhưng không vào vùng ven biển và đất liền nước ta lại có xu hướng tăng về số lượng. Bão có xu hướng tăng lên ở hai vùng Trung Bộ và Nam Bộ nhưng ở vùng Bắc Bộ lại có xu hướng giảm. Cường độ bão có xu hướng giảm, trong đó các cơn bão yếu có xu hướng giảm rõ rệt nhất. Kết quả [5] đưa ra một số nhận định về dao động chu kỳ nhiều năm và thập kỷ, số lượng bão trên khu vực TBTBD có xu thế biến đổi không như nhau đối với các cấp bão. Có sự giảm nhẹ của bão từ cấp 10 trở lên, đây có thể là nguyên nhân giảm nhẹ tổng số lượng bão và áp thấp nhiệt đới (ATNĐ) trên toàn khu vực. Trên biển Đông tổng số bão và áp thấp nhiệt đới có $\mathrm{xu}$ hướng tăng nhẹ. Xu thế này có sự đóng góp của $A T N Đ$ vào bão cấp 8 và 9 . Các loại bão có cường độ mạnh, đặc biệt bão cấp 10 và 11 lại có xu thế giảm. Theo [6] thì nhận định bão và áp thấp nhiệt đới đổ bộ và gây nên các tác động lên đất liền ven biển Việt Nam tập trung ở vùng biển Bắc Bộ và Bắc Trung Bộ, trong đó cực đại trên đoạn bờ Hà Tĩnh - Nam Nghệ An. Dải ven bờ Bình Bịnh - Quảng Ngãi có tẩn suất bão độ bộ lớn bờ biển Việt Nam, tổng số bão và áp thấp nhiệt đới không có xu thế rõ đối với vùng bờ phía bắc, trong khi tăng lên tại Trung Bộ và phía Nam.

Trong bài báo này, chúng tôi tập trung đánh giá xu thể biến đổi cả về số lượng, cường độ và quỹ đạo của những cơn bão (XTNĐ) trên khu vực Biển Đông dựa trên những nguồn số liệu mới và chi tiết nhất hiện có [13]. Những kết quả phân tích chi tiết những đặc trưng thống kê và phân bố số lượng và cường độ bão chi tiết theo số liệu cập nhật đến hết năm 2013.

\section{TÀI LIỆU VÀ PHƯƠNG PHÁP NGHIÊN CứU}

\section{Số liệu sử dụng}

Số liệu về bão sử dụng trong báo cáo được thu thập từ dữ liệu lưu trữ trên các website của RSMC (Regional Specialized Meteorological Centre) từ năm 1951 đến 2013 [13]. Các chuỗi số số liệu cơ bản về bão đã được thiết lập cho từng khu vực theo quy mô ảnh hưởng đến Biển Đông và bờ biển Việt Nam. Các khu vực được lựa chọn bao gồm: Biển Đông $(\mathrm{BĐ})$ và bờ biển Việt Nam (BBVN).
Ảnh hưởng của bão đến khu vực bờ biển Việt Nam được phân thành 7 vùng như trong hình 1. Các vùng được phân chia dựa trên cơ sở sau: khoảng cách từ bờ biển đến ranh giới phía ngoài được lấy bằng bán kính vùng gió mạnh từ cẩp 6 trở lên (khoảng 300-350 km). Ranh giới theo vĩ độ giữa các vùng được chia theo theo hai tiêu chí: ranh giới phân định các tỉnh và bề rộng tương đối của vùng theo hướng vĩ độ.

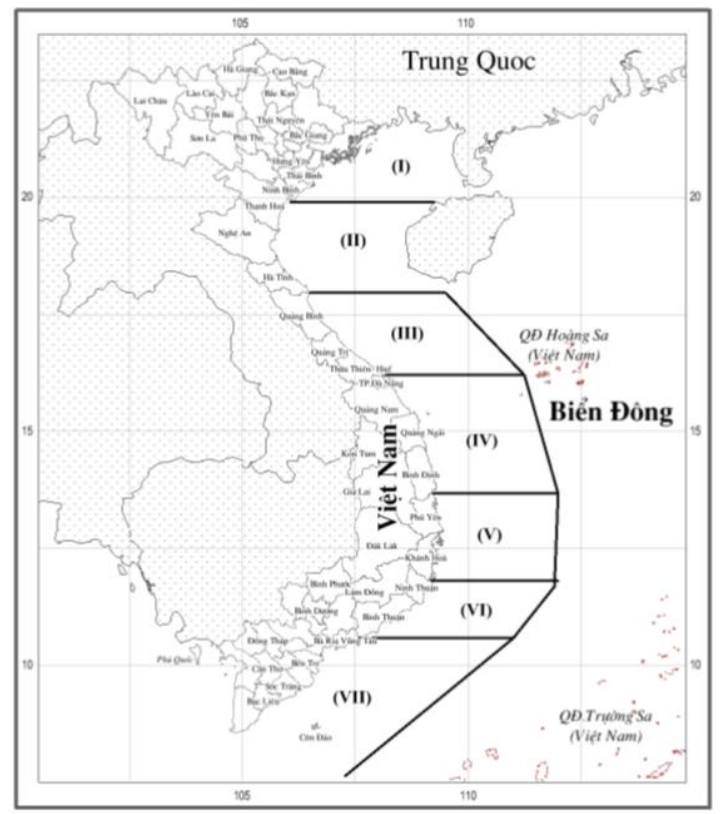

Hình 1. Sơ đồ phân vùng ảnh hưởng bão đến khu vực ven bờ biển Việt Nam

Vùng I: Quảng Ninh - NinhBình, từ vĩ tuyến tuyển $19,82^{\circ} \mathrm{N}$ trở lên;

Vùng II: Thanh Hoá - Hà Tĩnh, từ $19,82^{\circ} \mathrm{N}$ đến $17,95^{\circ} \mathrm{N}$;

Vùng III: Quảng Bình - Thừa Thiên Huế, từ $17,95^{\circ} \mathrm{N}$ đến $16,2^{\circ} \mathrm{N}$;

Vùng IV: Đà Nẵng - Bình Định, từ 16, $2^{\circ} \mathrm{N}$ đến $13,7^{0} \mathrm{~N}$;

Vùng V: Phú Yên - Khánh Hòa, từ $13,7^{0} \mathrm{~N}$ đến $11,8^{\circ} \mathrm{N}$;

Vùng VI: Ninh Thuận - Bình Thuận từ $11,80^{\circ} \mathrm{N}$ đến $10,57^{\circ} \mathrm{N}$;

Vùng VII: Nam Bộ từ vĩ tuyến $10,57^{\circ} \mathrm{N}$ trở xuống. 
Dư Văn Toán, Nguyễn Quốc Trinh, ...

Các chuỗi số liệu cho 7 đoạn bờ được thiết lập cho tất cả các nhóm cấp bão được phân tích thống kê nhằm đưa ra những đặc điểm phân bố và biến động của chúng.

\section{Phương pháp nghiên cứu}

Các công thức tính toán dựa theo các công thức của toán học thống kê, xác định các đặc trưng thống kê thông dụng đối với từng loại bão và từng khu vực biển cụ thể [12].

Giá trị trung bình được tính theo công thức sau:

$$
\bar{X}=\frac{\sum_{t=1}^{n} x_{t}}{n}
$$

Trong đó $\bar{X}$ là giá trị trung bình của nhân tố $\mathrm{x}, \mathrm{n}$ là độ dài của chuỗi số liệu của nhân tố $\mathrm{x}$. Khi tính toán giá trị trung bình nhiều năm (TBNN) từ năm 1951-2013, giá trị $\mathrm{n}=62$, trung bình từng thập niên 1951-1960, 1961-1970, 1981-1990,1991-2000 và 2001-2010, giá trị $\mathrm{n}=10$.

\section{Phát hiện $x u$ thế bằng phương pháp trung bình truọt}

Trung bình trượt được coi là công cụ phát hiện sơ bộ tính xu thế bằng cách san bằng những ảnh hưởng của biến đồi ngẫu nhiên đối với các chuỗi số liệu quan trắc. Trong hoàn cảnh dung lượng của chuỗi số liệu ngắn thường dùng 2 dạng trượt: trung bình trượt với $\mathrm{m}=5$, $\mathrm{m}=11$ (trọng lượng đồng đều). Trong nghiên cứu này sử dụng dạng trung bình trượt thứ 2 với $\mathrm{m}=11$.

Biến đổi chuỗi $\left\{\mathrm{x}_{\mathrm{t}}\right\}: \mathrm{x}_{1}, \mathrm{x}_{2}, \ldots \mathrm{x}_{\mathrm{n}}$ thành chuỗi $\left\{\tilde{x}_{t}\right\}$ không có hoặc có rất ít thành phần ngẫu nhiên:

$$
\tilde{x}_{\frac{m+1}{2}}+\tilde{x}_{\frac{m+1}{2}+1}+\ldots+\tilde{x}_{n-\frac{m+1}{2}}
$$

Bằng cách lấy trung bình của $\mathrm{m}$ thành phần liên tiếp làm trị số của thành phần giữa với điều kiện $m$ lẻ, $\frac{n}{10} \leq m \leq \frac{n}{3}$, khi đó trị số trung bình trượt với $\mathrm{m}$ thành phần $\mathrm{j}$ là $\mathrm{x}_{\mathrm{j}}$ có dạng:

$$
\widetilde{x}_{t}=\frac{1}{m} \sum_{t=j-\frac{m-1}{2}}^{j+\frac{m-1}{2}} x_{t}
$$

Trong chuỗi $\left\{\tilde{x}_{j}\right\}$ không có $\frac{m-1}{2}$ thành viên đầu và $\frac{m-1}{2}$ thành viên cuối.

\section{Lập phương trình $x u$ thế theo phưong pháp bình phương tối thiểu}

$$
b_{1}=\frac{\sum_{t=1}^{n}\left(x_{t}-\bar{x}\right)(t-\bar{t})}{\sum_{t=1}^{n}(t-\bar{t})^{2}} ; \quad b_{0}=\bar{x}-b_{1} t
$$

Các đặc trưng thu được từ phương trình $\mathrm{xu}$ thế bao gồm:

Tốc độ xu thế: $b_{1}$.

Gốc $\mathrm{xu}$ thế: $\mathrm{b}_{0}$.

Mức tăng hay giảm trong thời kỳ nghiên cứu.

$\mathrm{D}=\mathrm{b}_{1} \mathrm{n}$

Hệ số tương quan $\left(\mathrm{r}_{\mathrm{xt}}\right)$.

$$
r_{x t}=\frac{\sum_{t=1}^{n}\left(x_{t}-\bar{x}\right)(t-\bar{t})}{\left[\sum_{t=1}^{n}\left(x_{t}-\bar{x}\right)^{2} \sum_{t=1}^{n}(t-\bar{t})^{2}\right]^{\frac{1}{2}}}
$$

\section{Kiểm nghiệm xu thế}

Kiểm nghiệm độ tin cậy của hệ số tương quan $r_{x t}$.

Độ tin cậy của $\mathrm{r}_{\mathrm{xt}}$ được kiểm nghiệm bằng giả thiết $\mathrm{H}_{0}$ :

$$
\mathrm{H}_{0}: \mathrm{r}=0
$$

Tiêu chuẩn kiểm nghiệm ban đầu $\left(^{*}\right)$ là:

$(*) \begin{cases}\mathrm{r}-0 \geq \mathrm{d} \alpha & \mathrm{r} \text { được thừa nhận là đáng kể } \\ \mathrm{r}-0<0 & \mathrm{r} \text { là không đáng }\end{cases}$ $\mathrm{d} \alpha$ phải bảo đảm sao cho khi $\mathrm{H}_{0}$ đúng

$$
P\{|r-0| \geq d \alpha\}=\varepsilon
$$


Theo lý thuyết xác suất thống kê, biến $\mathrm{t}$ với:

$$
t=\frac{r}{\sqrt{1-r^{2}} / \sqrt{n-2}}
$$

Có phân bố Student nên tiêu chuẩn $\left(^{*}\right)$ được thay thế bằng $(* *)$ sau đây:

$$
(* *)\left\{\begin{array}{l}
|t| t \mid \geq \quad \text { r là đáng kể } \\
\mathbf{t} \mid<t \alpha \quad \text { r là không đáng kể }
\end{array}\right.
$$

Với: điều kiện khi $\mathrm{H}_{0}$ đúng $P\{|t| \geq t \alpha\}=\alpha$

Theo phương pháp nói trên, hệ số tương quan với dung lượng mẫu $\mathrm{n}$ coi là đáng kể khi thỏa mãn tiêu chuẩn tương ứng với $\alpha=0,05$ và 0,01được thể hiển trong bảng 1 .

Bảng 1. Tiêu chuẩn tin cậy của $r$

\begin{tabular}{ccccccccccc}
\hline $\mathbf{n - 2}$ & $\mathbf{1 0}$ & $\mathbf{2 0}$ & $\mathbf{3 0}$ & $\mathbf{4 0}$ & $\mathbf{5 0}$ & $\mathbf{6 0}$ & $\mathbf{7 0}$ & $\mathbf{8 0}$ & $\mathbf{9 0}$ & $\mathbf{1 0 0}$ \\
$\alpha=0,05$ & 0,576 & 0,423 & 0,349 & 0,304 & 0,273 & 0,250 & 0,232 & 0,217 & 0,205 & 0,195 \\
$\alpha=0,01$ & 0,708 & 0,537 & 0,449 & 0,393 & 0,362 & 0,325 & 0,302 & 0,283 & 0,267 & 0,254 \\
\hline
\end{tabular}

Kiểm nghiệm sự tồn tại của xu thế trong các chuỗi khí hậu theo phương pháp Spearman.

Từ chuỗi số liệu ban đầu $\left\{\mathrm{x}_{\mathrm{t}}\right\}$

$$
\mathrm{x}_{1}, \mathrm{x}_{2}, \ldots \mathrm{x}_{\mathrm{n}}
$$

Lập chuỗi trình tự $\left\{\mathrm{y}_{\mathrm{i}}\right\}$

$$
\mathrm{y}_{1}, \mathrm{y}_{2}, \ldots \mathrm{y}_{\mathrm{n}}
$$

Trong đó $\mathrm{y}_{1}<\mathrm{y}_{2}<\ldots<\mathrm{y}_{\mathrm{n}}$

Chuỗi $\left\{\mathrm{x}_{\mathrm{t}}\right\}$ được coi là có $\mathrm{xu}$ thế khi $\left\{\mathrm{x}_{\mathrm{t}}\right\}$ tương tự $\left\{\mathrm{y}_{\mathrm{i}}\right\}$, nói cách khác, khi các trị số $\mathrm{t}$ của $\mathrm{x}_{\mathrm{t}}$ gần đúng với $\mathrm{i}$ trong $\mathrm{y}_{\mathrm{i}}$.

Lập hệ số tương quan hạng $\mathrm{r}_{\mathrm{s}}$ với:

$$
r_{s}=1-\frac{6}{n\left(n^{2}-1\right)} \sum_{t, i=1}^{n}\left[t\left(x_{t}\right)-i\left(y_{i}\right)\right]^{2}
$$

Theo Spearman, kỳ vọng của $\mathrm{r}_{\mathrm{s}}$ bằng không $\left(\mathrm{M}\left(\mathrm{r}_{\mathrm{s}}\right)=0\right)$ và phương sai của $\mathrm{r}_{\mathrm{s}}$ được tính bằng:

$$
D\left(r_{s}\right)=\frac{1}{n-1}
$$

Chuỗi $\left\{\mathrm{x}_{\mathrm{t}}\right\}$ coi là không có xu thế khi giả thiết ban đâu $\mathrm{H}_{0}: \mathrm{r}_{\mathrm{s}}=0$ được chấp nhận với mức tin cậy $\alpha$.

Tiêu chuẩn kiểm nghiệm:

$$
\begin{aligned}
& \left\{\left|r_{s}\right| \geq \alpha\right\} \text {, bác bỏ giả thiết } \\
& \left\{\left|r_{s}\right|<\alpha\right\} \text {, chấp nhận giả thiết }
\end{aligned}
$$

d phải xác định sao cho khi $\mathrm{H}_{0}$ đúng

$$
P\left\{\left|r_{s}\right| \geq d\right\}=\alpha
$$

Đặt $u=\frac{r_{s}-M\left(r_{s}\right)}{\sqrt{D\left(r_{s}\right)}}$ và $U \alpha=\frac{d}{\sqrt{D\left(r_{s}\right)}}$

Tiêu chuẩn kiểm nghiệm trở thành:

$$
\begin{aligned}
& |u| \geq u_{0} \text {, bác bỏ giả thiết } \\
& |u|<u_{0} \text {, chấp nhận giả thiết }
\end{aligned}
$$

Bởi vì u có phân bố chuẩn chuẩn hóa $\mathrm{N}(0,1)$ và do đó:

$$
\frac{\alpha}{2}=\int_{u_{0}}^{e} \frac{1}{\sqrt{2 \pi}} e^{\frac{1}{2} t^{2}} d t
$$

Với $\alpha=0,05, \mathrm{u}_{\alpha}=1,96$

Như vậy, khi $|u| \geq 1,96$ chuỗi khí hậu được coi là có xu thê rõ rệt và ngược lại. Khi $|u|<1,96$ chuỗi được coi là không có xu thế.

\section{KẾT QUẢ}

Trong thời kỳ 1951 - 2013, trên khu vực Tây Bắc Thái Bình Dương (TBTBD) có 1.619 cơn bão (XTNĐ) hoạt động, trung bình có khoảng 26,1 cơn/năm. Khu vực Biển Đông (BĐ) có 695 XTNĐ hoạt động, trung bình có khoảng 11,03 cơn/năm. Năm có nhiều XTNĐ nhất là năm 1964 với 21 cơn, năm có ít XTNĐ nhất là năm 1969 với 5 cơn. Khu vực ven biển Việt Nam (VBVN) có 327 XTNĐ hoạt động, trung bình có khoảng 5,2 
Dư Văn Toán, Nguyễn Quốc Trinh, ...

cơn/năm. Năm có nhiều xoáy thuận hoạt năm 1957, 1958 và 2002, với 1 cơn động nhất là 1973, với 11 cơn, ít nhất là các (bảng 2, 3, 4).

Bảng 2. Số lượng XTNĐ theo tháng thời kỳ 1951-2013 (cơn)

\begin{tabular}{|c|c|c|c|c|c|c|c|c|c|c|c|c|c|}
\hline $\begin{array}{c}\text { Khu } \\
\text { vực/Tháng }\end{array}$ & 1 & 2 & 3 & 4 & 5 & 6 & 7 & 8 & 9 & 10 & 11 & 12 & Tổng \\
\hline TBTBD & 28 & 11 & 24 & 42 & 64 & 104 & 237 & 339 & 307 & 236 & 153 & 74 & 1619 \\
\hline $\mathrm{B} \oplus$ & 7 & 1 & 9 & 11 & 28 & 66 & 112 & 112 & 124 & 98 & 93 & 34 & 695 \\
\hline VBVN & 1 & 1 & 3 & 4 & 8 & 22 & 40 & 46 & 61 & 70 & 54 & 17 & 327 \\
\hline $\begin{array}{c}\text { Tỷ lệ } \\
\text { VBVN/BĐ }\end{array}$ & 0,14 & 1,00 & 0,33 & 0,36 & 0,29 & 0,33 & 0,36 & 0,41 & 0,49 & 0,71 & 0,58 & 0,50 & 0,47 \\
\hline
\end{tabular}

Bảng 3. Số lượng, tần suất và tỷ lệ bão Biển Đông theo tháng thời kỳ 1951-2013

\begin{tabular}{|c|c|c|c|c|c|c|c|c|c|c|c|c|c|}
\hline Tháng & 1 & 2 & 3 & 4 & 5 & 6 & 7 & 8 & 9 & 10 & 11 & 12 & Tổng \\
\hline $\mathrm{B} \oplus$ & 7 & 1 & 9 & 11 & 28 & 66 & 112 & 112 & 124 & 98 & 93 & 34 & 695 \\
\hline Trung bình & 0,11 & 0,02 & 0,14 & 0,17 & 0,44 & 1,05 & 1,78 & 1,78 & 1,97 & 1,56 & 1,48 & 0,54 & 11,03 \\
\hline Tỷ lệ \% & 1,01 & 0,14 & 1,29 & 1,58 & 4,03 & 9,50 & 16,12 & 16,12 & 17,84 & 14,10 & 13,38 & 4,89 & 100,00 \\
\hline
\end{tabular}

Bảng 4. Số lượng, tần suất và tỷ lệ \% theo tháng bão vào vùng bờ Việt Nam thời kỳ 1951-2013

\begin{tabular}{|c|c|c|c|c|c|c|c|c|c|c|c|c|c|}
\hline Tháng & 1 & 2 & 3 & 4 & 5 & 6 & 7 & 8 & 9 & 10 & 11 & 12 & Tổng \\
\hline VBVN & 1 & 1 & 3 & 4 & 8 & 22 & 40 & 46 & 61 & 70 & 54 & 17 & 327 \\
\hline $\begin{array}{l}\text { Trung } \\
\text { bình }\end{array}$ & 0,02 & 0,02 & 0,05 & 0,06 & 0,13 & 0,35 & 0,63 & 0,73 & 0,97 & 1,11 & 0,86 & 0,27 & 5,19 \\
\hline Tỷ lệ & 0,31 & 0,31 & 0,92 & 1,22 & 2,45 & 6,73 & 12,23 & 14,07 & 18,65 & 21,41 & 16,51 & 5,20 & 100 \\
\hline
\end{tabular}

Trên các hình $2 a, 2 b, 2 c$ dễ dàng nhận thấy (đường nét đứt trung bình trượt 10 năm) hai chu kỳ biến động về số lượng bão trên khu vực TBTBD, BĐ và VBVN, mỗi chu kỳ dài khoảng 30 năm. Phân tích hồi quy số lượng cơn bão với mức độ tin cậy đạt $99 \%$ theo số liệu trung bình trượt thập kỷ (10 năm) cho thấy tốc độ suy giảm số lượng theo xu hướng giảm khoảng 0,8 cơn/thập kỷ trên khu vực TBTBD (hình $2 \mathrm{a}$ ) và giảm khoảng 0,2 cơn/thập kỷ trên khu vực $\mathrm{BĐ}$ (hình $2 b$ ). Khu vực VBVN có xu thế giảm khoảng 0,2 cơn/thập kỷ, với mức đảm bảo 95\% (hình 2c).
Trong 6 thập kỷ, 1951-2010, trên khu vực TBTBD số lượng bão biến đổi tăng và giảm đan xen qua các thập kỷ, riêng thập kỷ cuối số lượng bão giảm xuống ít hơn trung bình nhiều năm (TBNN). Trên khu vực Biển Đông, thập kỷ 6 - thập kỷ cuối 2001-2010 số lượng bão cũng giảm xuống ít hơn TBNN, các thập kỷ còn lại biến đổi theo xu hướng tăng từ thập kỷ 1951-1960 sang thập kỷ 1961-1970, sau đó giảm dần qua các thập kỷ tiếp theo, nhưng sự thay đổi này rất nhỏ so với TBNN. Như vây cho thấy xu thế biến đổi về số lượng bão qua các thập kỷ thể hiện không thật sự rõ ràng. 
Một số đánh giá thống kê về tính chất của bão ...

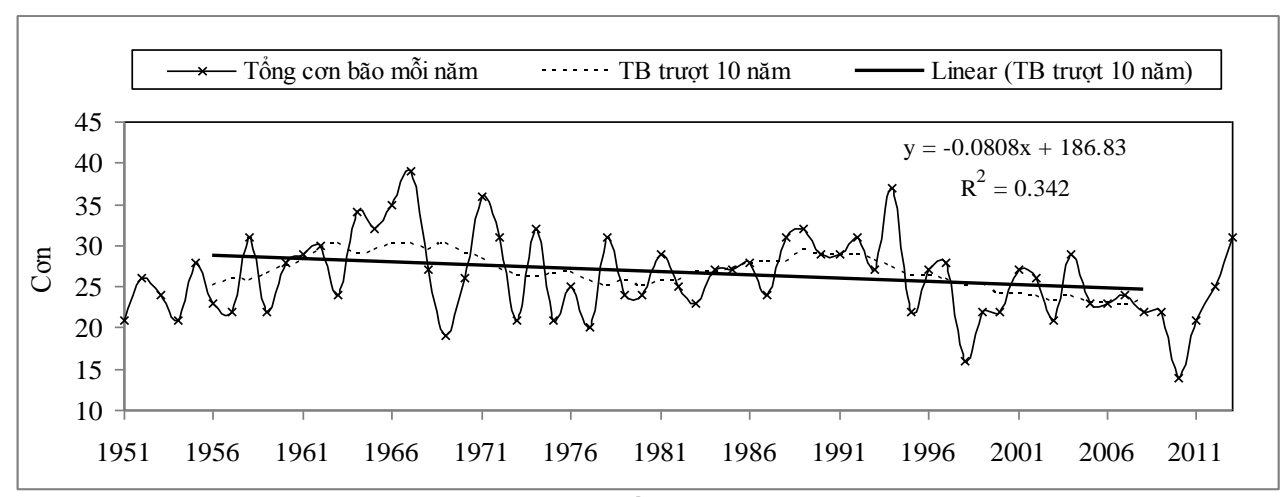

a. Khu vực Tây Bắc Thái Bình Dương

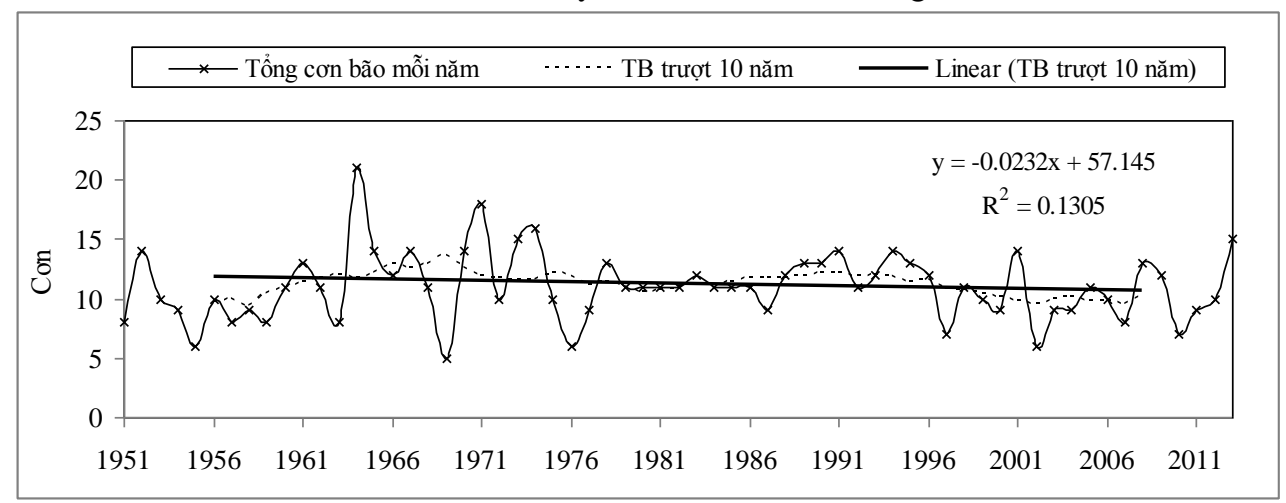

b. Khu vực Biển Đông

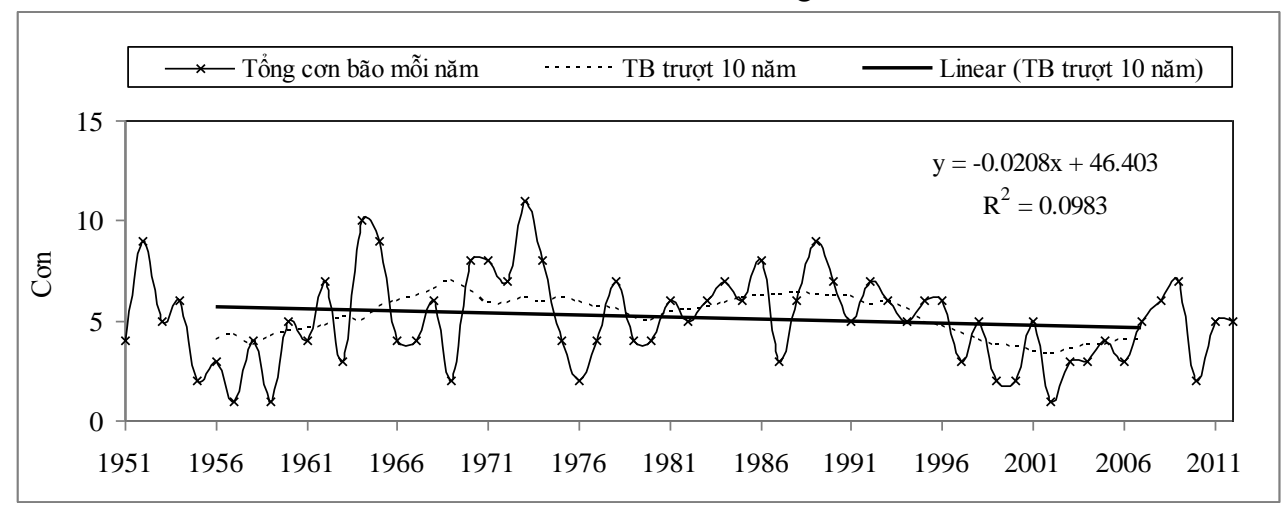

c. Khu vực ven biển Việt Nam (VBVN)

Hình 2. Biến thiên số lượng bão thời kỳ 1951-2013

Tần số XTNĐ trên TBTBD và Biển Đông biến đổi trong các thập kỷ khác nhau được trình bày trong hình 3 . Trong thời kỳ nghiên cứu, XTNĐ trên Biển Đông nhiều nhất trong thập kỷ 1961 - 1970 và ít nhất trong thập kỷ 1951 - 1960. Trên khu vực TBTBD thập kỷ 1961-1970 có nhiều XTNĐ nhất, ít nhất là thập kỷ 2001-2010.

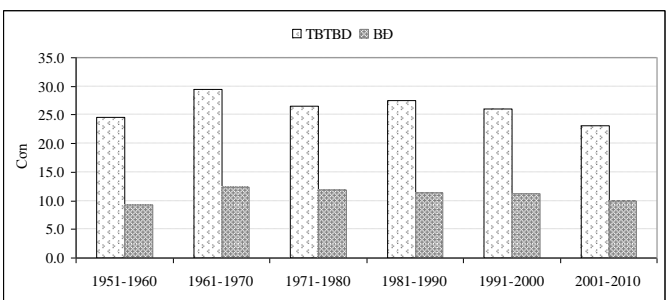

Hình 3. Số lượng XTNĐ trung bình theo thập kỷ 


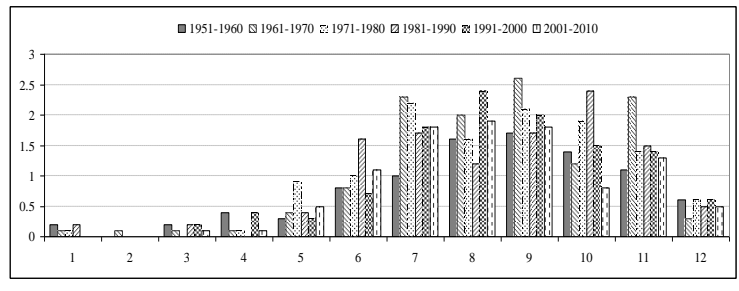

Hình 4. Biến thiên số lượng bão trung bình tháng trên Biển Đông qua từng thập kỷ

Trên hình 5 cho thấy, số XTNĐ trung bình các thập kỷ hoạt động ven bờ biển Việt Nam. Số XTNĐ này tăng dần và đạt cực đại ở thập kỷ 1981-1990, sau đó giảm dần đến thập kỷ 2001-2010.

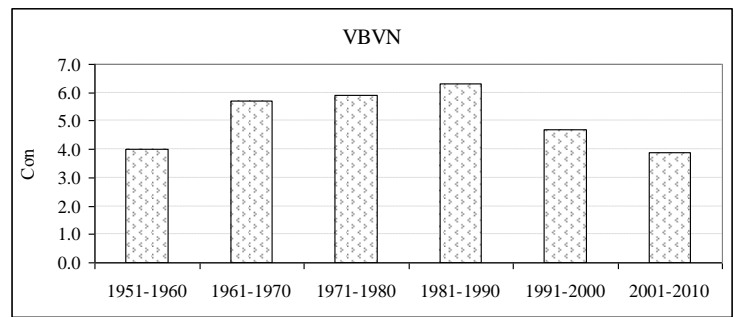

Hình 5. Số lượng XTNĐ trung bình theo thập kỷ VBVN

Số lượng xoay thuận nhiệt đới hoạt động trên Biển Đông phân phối không đồng đều trong các tháng của năm. Thời gian từ tháng 5 đến tháng 12 được coi là mùa bão trên Biển Đông. Trong mùa bão, XTNĐ xuất hiện tập trung vào các tháng $7,8,9,10$ và 11. Tháng 9 là tháng có số tần suất xuất hiện XTNĐ lớn nhất 1,97 cơn, tháng có ít XTNĐ nhất là tháng 2 , với tần suất 0,02 cơn, trong 63 năm mới xuất hiện 1 XTNĐ vào năm 1965 (xem bảng 2). Tháng 11 năm 1964 là tháng có số lượng XTNĐ lớn nhất với 6 cơn, năm 2013 có 4 cơn. Mùa bão ở Biển Đông cũng được thể hiện rõ thêm qua sự biến động số lượng bão trên khu vực Biển Đông theo tháng qua các thập kỷ như trình bày trong hình 7 . Số lượng bão trung bình tháng trên khu vực Biển Đông qua 6 thập kỷ cho ta thấy rõ mùa bão chính trong khu vực kéo dài từ tháng 7 đến hết tháng 11 . Tháng có số lượng bão trung bình lớn nhất biến đồi qua từng thập kỷ.

Mùa XTNĐ hay mùa bão ở Biển Đông biến đổi nhiều từ năm này qua năm khác, thập kỷ này sang thập kỷ khác, cả về thời gian bắt đầu, thời kỳ cao điểm cũng như thời gian kết thúc. Bảng 5 trình bày tần suất thời điểm bắt đầu và kết thúc mùa bão theo thập kỷ. Trong 60 năm, từ 1951 đến 2010, theo thống kê thời gian bão bắt đầu hoạt động theo tháng cho thấy mùa bão được bắt đầu sớm nhất vào tháng 1 là có 7 năm chiếm khoảng $1 \%$. Thực tế này chỉ ra rằng đây chính là mùa mưa bão của năm trước kéo dài sang năm sau và như vậy tháng 1 chính thức là tháng hoạt động muộn nhất của mùa bão. Không có mùa bão nào bắt đầu vào tháng 2 , chứng tỏ đây là tháng giao mùa bão, thể hiện phân cách rõ ràng giữa các mùa bão. Có 8 năm màu bã bắt đầu vào tháng 3 chiếm khoảng $12,9 \%$, thực tế tháng này là tháng bắt đầu của mùa mưa bão mới, các cơn bão đầu màu xuất hiện trong tháng này. Mùa bão bắt đầu vào tháng 4 có 6 năm chiếm khoảng 9,7\%, tháng 5 và 6 có 17 năm có bão chiếm khoảng $27,4 \%$. Mùa bão bắt đầu vào tháng 7 có 8 năm chiếm $12,9 \%$ là tháng bắt đầu mùa mưa bão muộn nhất trong năm. Tương tự như vậy, thời gian kết thúc mùa mưa bão cũng được thống kê và đưa ra kết quả như sau: Thời điểm kết thúc mùa bão sớm nhất vào tháng 9 có 4 năm $(1955,1969,1976$ và 2002) chiếm $6,5 \%$. Mùa bão kết thúc vào tháng 11 có tỷ trọng lớn nhất, với 27 năm chiếm 43,5\%, kế tiếp đó là kết thúc vào tháng 12 với 25 năm và chiếm $40,3 \%$, vào tháng 10 có 6 năm chiếm $9,7 \%$.

Như vậy, mùa bão ở khu vực Biển Đông bắt đầu sớm hất là tháng 3 và tập trung cao vào tháng 5 và tháng 6 , mùa bão kết thúc tập trung vào tháng 11 và tháng 12 và muộn nhất là sang tháng 1 năm sau. Trong cả thời kỳ dài 60 năm từ 1951-2010 luôn có bão trong 3 tháng liên tiếp 7,8 và 9 , điều này cho thấy thời gian hoạt động của XTNĐ trong khu vực Biển Đông tối thiểu là 3/12 tháng, tương đương $25 \%$. 
Bảng 5. Tần suất tháng bắt đầu, kết thúc mùa bão (\%) và mùa bão trung bình cho các thập kỷ, khu vực Biển Đông

\begin{tabular}{|c|c|c|c|c|c|c|c|c|c|c|c|c|c|}
\hline \multirow{2}{*}{ Thời điểm } & \multirow{2}{*}{ Thập kỷ } & \multicolumn{12}{|c|}{ Tháng } \\
\hline & & 1 & 2 & 3 & 4 & 5 & 6 & 7 & 8 & 9 & 10 & 11 & 12 \\
\hline \multirow{6}{*}{$\begin{array}{l}\text { Bắt đầu mùa } \\
\text { bão }\end{array}$} & $1951-1960$ & 20 & & 20 & 20 & 10 & 30 & & & & & & \\
\hline & $1961-1970$ & 10 & & 10 & & 30 & 10 & 40 & & & & & \\
\hline & $1971-1980$ & 10 & & & 10 & 40 & 30 & 10 & & & & & \\
\hline & $1981-9990$ & 20 & & 10 & & 30 & 40 & & & & & & \\
\hline & $1991-2000$ & & & 20 & 20 & 20 & 30 & 10 & & & & & \\
\hline & $2001-2010$ & & & 10 & 10 & 40 & 20 & 20 & & & & & \\
\hline \multirow{6}{*}{$\begin{array}{l}\text { Kết thúc mùa } \\
\text { bão }\end{array}$} & $1951-1960$ & & & & & & & & & 10 & 20 & 20 & 50 \\
\hline & $1961-1970$ & & & & & & & & & 10 & 10 & 50 & 30 \\
\hline & $1971-1980$ & & & & & & & & & 10 & & 50 & 40 \\
\hline & $1981-1990$ & & & & & & & & & & & 50 & 50 \\
\hline & $1991-2000$ & & & & & & & & & & 10 & 60 & 30 \\
\hline & $2001-2010$ & & & & & & & & & 10 & 20 & 40 & 30 \\
\hline
\end{tabular}

\section{Vùng ven biển Việt Nam}

Đối với 7 vùng ven biển ven biển Việt Nam (hình 1), một XTNĐ có thể hoạt động trên nhiều vùng trong quá trình di chuyển và biến đổi của nó. Số lượng XTNĐ hoạt động có sự biến động mạnh giữa các vùng, và có $\mathrm{xu}$ hướng chung là giảm dần từ Bắc vào $\mathrm{Nam}$ (hình 6).

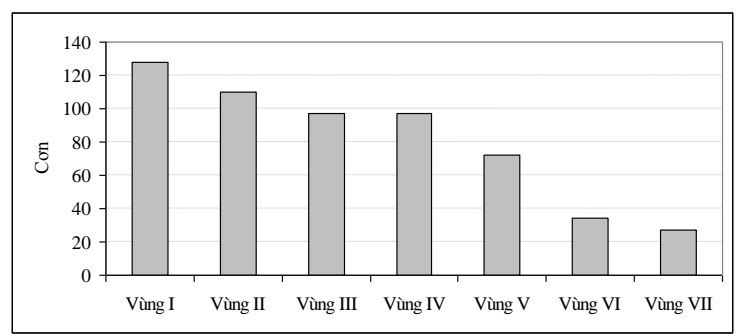

Hình 6. Số lượng XTNĐ thời kỳ 1951-2013

Kết quả phân tích hồi quy cho thấy xu hướng biến đổi về số lượng XTNĐ qua các năm của các vùng có sự khác nhau. Sô lượng XTNĐ trong các vùng $I$, IV và VII có $x u$ hướng giảm, trong khi các vùng II, III, V và VI có xu hướng tăng lên. Hình 7 trình bày số lượng XTNĐ từng năm trong 7 vùng.

Kết quả thống kê số lượng XTNĐ theo thập kỷ cho thấy 3 nhóm xu thế rõ ràng. Nhóm thứ nhất gồm các vùng I, II, III và IV, nhóm thứ hai gồm vùng $\mathrm{V}$ và nhóm ba gồm vùng VI và VII (hình 8). Nhóm một, số lượng XTNĐ tập trung vào hai thập kỷ 1971-1980 và 1981-1990, hai thập kỷ 1961-1970 và 1981-1990 có số lượng XTNĐ nhỏ nhất. Nhóm 2, số lượng XTNĐ lớn nhất trong thập kỷ 1971-1980. Nhóm 3, số lượng XTNĐ phân bố thành hai đỉnh vào các thập kỷ 1961-1970 và 1991-2000.

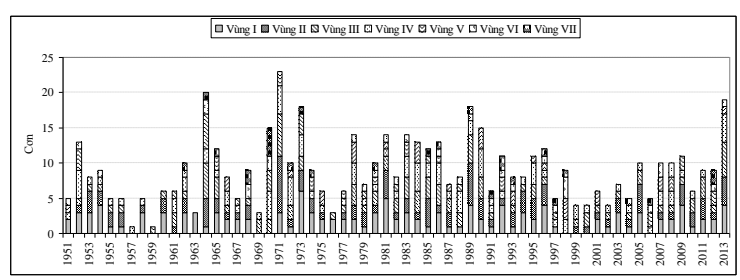

Hình 7. Số lượng XTNĐ 7 vùng ven bờ Việt Nam

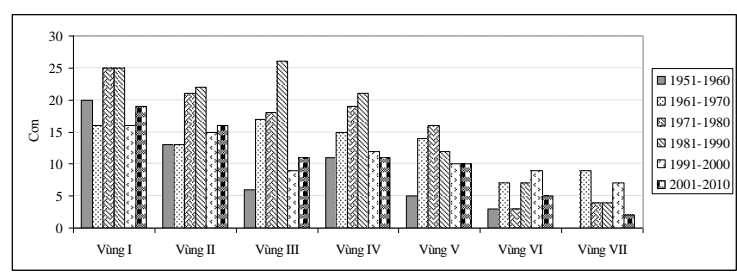

Hình 8. Số lượng XTNĐ trung bình thập kỷ của 7 vùng ven biển Việt Nam

Kết quả phân tích hồi quy chuỗi số liệu trung bình trượt 10 năm vị trí đổ bộ trung bình năm của bão theo vĩ độ cho thấy, điểm đồ bộ có xu hướng dịch xuống phía Nam khoảng 0,015 độ/năm (hình 9). 


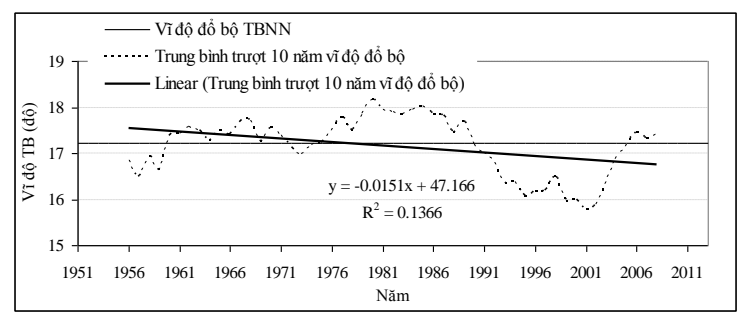

Hình 9. Sự thay đổi vị trí đổ bộ trung bình năm theo vĩ độ và xu thế biến đồi theo trung bình trượt 10 năm

Kết quả phân tích hồi quy tuyến tính đối với chuỗi số liệu tốc độ gió (hình 10 ), của các cơn bão cho thấy xu thế giảm rất nhỏ, với mức đảm bảo $95 \%$. Gió có tốc độ cực đại trong các cơn bão là khoảng $53 \mathrm{~m} / \mathrm{s}$, đạt lớn nhất năm 2006 với $58 \mathrm{~m} / \mathrm{s}$. Lượng mưa cực đại trong bão biến đổi qua từng cơn bão, từng năm, trung bình trong vào khoảng trên 400 , có xu thế tăng nhẹ (hình 11). Tuy nhiên, số liệu về lượng mưa thu thập chưa đủ dài, xu thế biến đổi của nó chưa đủ độ tin cậy theo lý thuyết thống kê.

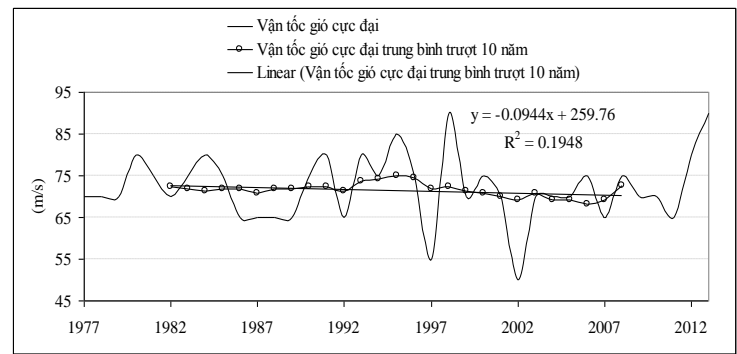

Hình 10. Xu thế biến đổi của tốc độ gió cực đại trong bão trên biển Đông

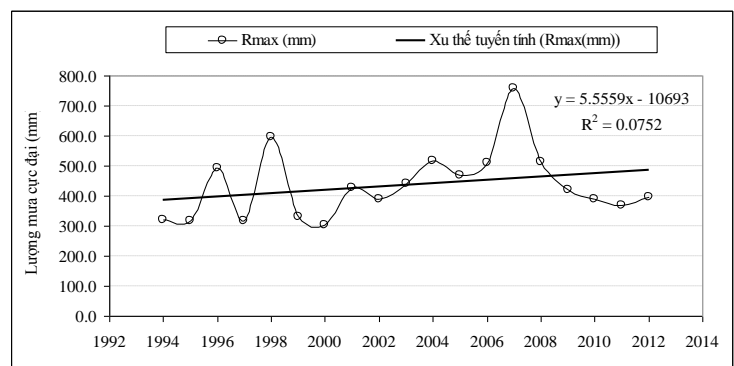

Hình 11. Xu thế lượng mưa cực đại trong bão BBVN

\section{KẾT LUẬN}

Số lượng các cơn bão trong thời kỳ 19512013 hoạt động trên Biển Đông là 695 cơn và trung bình năm là hơn 11 cơn, và tại vùng BBVN là khoảng 5,2 cơn/năm.

Gió có tốc độ cực đại trong các cơn bão là khoảng $53 \mathrm{~m} / \mathrm{s}$, đạt lớn nhất năm 2006 với $58 \mathrm{~m} / \mathrm{s}$. Lượng mưa cực đại trong bão biến đổi qua từng cơn bão, từng năm, trung bình trong vào khoảng trên 400 , có xu thế tăng nhẹ.

Tháng hoạt động chính của mùa bão là 7 , 8 và 9 , số lượng bão đổ bộ vào Việt Nam theo 7 phân vùng giảm dần hướng Bắc Nam từ vùng $\mathrm{I}$ đến vùng VII. Tổng hơn 120 cơn vùng I gấp 4 lần so với vùng VII (khoảng 30 cơn).

Xu thế biến đổi về số lượng bão qua 6 thập niên theo số liệu hiện có từ 1951 đến 2010 thể hiện không thật sự rõ ràng với xu thế chung là giảm nhẹ 0,1 cơn/thập kỷ. Như vậy có thể nói chuỗi số liệu quan trắc các cơn bão hay XTNĐ trong 60 năm chưa đủ dài để mô tả hết sự biến động toàn diện của biến động cơn bão nói riêng.

Vấn đề thống kê và phân tích số lượng bão đến vùng biển Đông và ven bờ Việt $\mathrm{Nam}$ cần được xem là vấn đề phải được liên tục nghiên cứu và phân tích, đánh giá nhằm đảm bảo thông tin cho công tác phòng chống thiên tai bão đối với các hoạt động kinh tế biển và ven bờ. Cần phải xây dựng và tự động hóa bộ cơ sở dữ liệu thống kế đầy đủ về chuỗi dài số liệu cơn bão cùng tần suất, tốc độ, hướng, gió, mưa, điểm đổ bộ, vùng đổ bộ bão. Cần có thêm nhiều nghiên cứu thống kê để phát hiện ra được các quy luật - quy trình của bão Biển Đông và ven bờ Việt Nam và các tác động kinh tế xã hội môi trường của các địa phương theo phân bố vùng nhằm đề xuất giải pháp phòng chống thiên tai bão lũ hợp lý và hiệu quả.

\section{TÀI LIỆU THAM KHẢO}

1. Nguyễn Văn Âu, 2002. Địa lý tự nhiên biển Đông. Nxb. Đại học Quốc gia Hà Nội, 2002. 180 tr.

2. Vũ Thanh Hằng, Ngô Thị Thanh Hương, Phan Văn Tân, 2010. Đặc điểm hoạt động của bão ở vùng biển gần bờ Việt Nam giai đoạn 1945-2007. Tạp chí Khoa học ĐHQGHN, Khoa học Tự nhiên và Công nghệ 26, Số 3S, 344-353. 
3. Nguyễn Văn Tuyên, 2007. Xu hướng hoạt động của xoáy thuận nhiệt đới trên Tây Bắc Thái Bình Dương và Biển Đông theo các cách phân loại khác nhau. Tạp chí Khí tượng Thủy vằn 559, 14-21.

4. Phạm Ngọc Toàn, Phan Tấn Đắc, 1993. Khí hậu Việt Nam. Nxb. KHKT. 350 tr.

5. Đinh Văn Uu, Phạm Hoàng Lâm, 2005. Biến động mùa và nhiều năm của trường nhiệt độ mặt nước biển và sự hoạt động của bão tại khu vực Biển Đông. Tạp chí Khoa học ĐHQGHN, Khoa học Tự nhiên và Công nghệ XXI 3PT, 12-19.

6. Đinh Văn Uu, 2009. Đánh giá quy luật biến động dài hạn và xu thế biến đổi số lượng bão và áp thấp nhiệt đới trên khu vực Tây Thái Bình Dương, Biển Đông và ven biển Việt Nam. Tạp chí Khoa học ĐHQGHN, Khoa học Tự nhiên và Công nghệ 25 3S, 542-550.

7. Đinh Văn $U$ u, 2010. Sự biến động hoạt động và đổ bộ của bão nhiệt đới vào bờ biển Việt Nam. Tạp chí Khoa học ĐHQGHN, Khoa học Tự nhiên và Công nghệ, Tập 26, Số 3S, 479-455.

8. Đinh Văn Uu, 2011. Đặc điểm biến động bão và áp thấp nhiệt đới ảnh hưởng trực tiếp đến đất liền Việt Nam. Tạp chí Khoa học ĐHQGHN, Khoa học Tự nhiên và Công nghệ 27, Số 1S, 266-272.

9. Viện Khoa họ và Công nghệ Việt Nam, 2009. Biển Đông. Tập 1. Nxb. KHTN\&CN. $600 \mathrm{tr}$

10. C. W. Landsea, R. A. Pielke, A. M. Mestas-Nunez, J. A. Knaff, 1999. Atlantic basin hurricanes: Indices of climatic changes, Climatic Change 42, 89-99.

11. M. Xu, M. Ying, Q. Yang, 2004. "Climate variability of tropical cyclone activities in Western North Pacific ocean", the $26^{\text {th }}$ Conference on Hurricanes and Tropical
Meteorology, Miami, Florida, 3-7 May, 2004, p. 10A.4.

12. D. S. Wilks, Statistical methods in the Atmospheric Sciences - Second Edition, 2006.

13. http://www.jma.go.jp/jma/indexe.html.

14. Белоненко Т. В., Шевченко Г. В., 2011. Методика оценки характеристик штормовых нагонов в различных районах океана. Спб, Гидрометеоиздат, 178 ctp

15. Григоркина Р. Г., Фукс В. Р., 1986. Воздействие тайфунов на океан. Л., Гидрометеоиздат, 1986, 242 ctp.

16. Данченков М. А., Гаврилов Г. М., 2000. Подъем вод у центральной части побережья Вьетнама в 1979-1988 гг. //Тр. ДВНИГМИ. 2000, вып. 140. С. 124-130.

17. Ластовеикий Е.И., Савельев А.В., 2000. Особенности гидрологического режима шельфовых вод Вьетнама осенью 1992 г. //Тр. ДВНИГМИ. 2000, вып. 140. С. 118 123.

18. Ластовеиякий Е. И., Стерхов С. H., Савельев А. В., 2000. Особенности геострофической циркуляции вод на шельфе Вьетнама и в прилегающих районах. //Тр. ДВНИГМИ. 2000, вып. 140. С. 131-136.

19. Ластовечкий Е. И., Савельев А. В., 2000. Особенности гидрологического режима вод шельфа Вьетнама в летний сезон. //Тр. ДВНИГМИ. 2000, вып. 140. С. 110117.

20. Юрасов Г. И., 1985. Исследование гидрологических условий на шельфе в районе дельты реки Меконг в период юго-западного муссона. //Океанологические исследования в Тихом океане. Владивосток. ДВНЦ АН CCCP. 1985. C. 56-60. 
Dư Văn Toán, Nguyễn Quốc Trinh, ...

\title{
A STATISTICAL ANALYSIS OF TYPHOONS IN THE PERIOD 1951 - 2013 IN VIETNAM'S COASTAL ZONES
}

\author{
Du Van Toan ${ }^{1}$, Nguyen Quoc Trinh ${ }^{2}$, Pham Van Tien ${ }^{3}$, \\ Luu Thi Toan ${ }^{4}$, Luu Thanh Trung ${ }^{5}$, Nguyen Ngoc Tien ${ }^{6}$ \\ ${ }^{1}$ Research Institute of Management of Sea and Islands \\ ${ }^{2}$ National Centre for Hydrometeorology Forecasting \\ ${ }^{3}$ Institute of Meteorology, Hydrology and Environment \\ ${ }^{4}$ Vietnam National University, Hanoi \\ ${ }^{5}$ Department for Science and Technology-Ministry of natural resources \\ and environment of the socialist republic of Vietnam \\ ${ }^{6}$ Institute of Marine Geology and Geophysics-VAST
}

\begin{abstract}
This article provided some evaluation methods of statistical analysis of typhoons in Vietnam. The results indicated that there were a total of 696 storms in Vietnamese sea for the period between 1951 - 2013, with the annual average more than 11 storms. Among them 327 storm approached coastline, bringing an average of 5.2 storms per year. Furthermore, hurricane season are likely to occur throught the month of July to September. The number of landing points were divided by 7 zones, taking account of decreasing gradient southward. The maximun, speed of storm was 58 metre per second and the maximum rainfall was over $400 \mathrm{~mm}$. The variation mechanism of Vietnam typhoons in the future were withdrawn in order to support assurance of weather information and disaster prevention.
\end{abstract}

Keywords: Vietnam typhoon, coastal zone, landing points, maximum wind speed, maximum rainfall, frequenoy per storm. 